\title{
Evaluation of Blended Oral English Teaching Based on the Mixed Model of SPOC and Deep Learning
}

\author{
Yanli Hui \\ Faculty of Foreign Languages and Business, Jiaozuo Normal College, Jiaozuo 454001, China \\ Correspondence should be addressed to Yanli Hui; 1295004004@jzsz.edu.cn
}

Received 8 September 2021; Revised 14 October 2021; Accepted 26 October 2021; Published 8 November 2021

Academic Editor: Chenxi Huang

Copyright (C) 2021 Yanli Hui. This is an open access article distributed under the Creative Commons Attribution License, which permits unrestricted use, distribution, and reproduction in any medium, provided the original work is properly cited.

\begin{abstract}
With the deep integration of "internet + education" and the continuous advancement of education reform, blended teaching has become the main method of university education reform. Blended education combines the advantages of traditional education and online education to complement each other. It not only takes advantage of the flexibility and autonomy of online education but also retains the benefits of emotional communication between teachers and students in offline education. With the increase in practical exploration of blended teaching in universities, teaching evaluation is an important part of teaching, and blended teaching evaluation should also attract attention. The purpose of this paper is to study the mixed oral English teaching evaluation based on the mixed mode of SPOC and deep learning. On the basis of analyzing the teaching design principles of the mixed mode of SPOC and deep learning and the principles of constructing the teaching evaluation after half a semester of teaching investigations conducted by the two classes of English majors, the impact of the SPOC and deep learning mixed teaching mode on students' spoken English was studied through the method of covariance analysis. The experimental results show that the mixed teaching mode of SPOC and deep learning has been able to fully stimulate students' interest in oral English learning and improve students' oral English ability, critical thinking of students, ability to solve problems, group cooperation, and effective communication. Self-directed learning and self-reflection have all had a positive impact.
\end{abstract}

\section{Introduction}

With the acceleration of the globalization of the world economy, English has become a commonly used language throughout the world and has played a great role in promoting economic, cultural, academic, and political exchanges and cultural exchanges between various ethnic groups $[1,2]$. Spoken language is its external form of expression, which has attracted great attention from all countries in the world. However, for a long time, in our country, oral English teaching often adopts the teaching method of "students learn passively under the guidance of teachers, and the interaction between teachers and students is weakened." Due to the limited resources of textbooks and the lack of a real language environment, students' oral English expression skills are generally weak, and phenomena such as "high scores and low energy" and "dumb English" still exist. In order to change this situation, it is urgent to make full use of modern information technology and adjust the college English teaching mode [3, 4]. English is a West Germanic language branch. It was first used by medieval Britain and has become the most widely used language in the world because of its vast colonies. The Anglo tribe, the ancestor of the British, is one of the Germanic tribes that later migrated to the island of Great Britain, known as England. Both names come from Anglia on the Baltic peninsula. The language is closely related to Frisian and lower Saxon. Its vocabulary is influenced by other Germanic languages, especially Nordic, and is largely written in Latin and French.

In recent years, many scholars have conducted research on mixed nurse teaching and have achieved good results. Some scholars believe that it is the use of the Pan-Asian SPOC concept and the in-depth integration of traditional classroom teaching theories at home and abroad. Besides, SPOC perfectly adapts to the exclusiveness of elite 
universities and the values of pursuing high achievements; SPOC model has low cost and can be used to generate income, which provides a sustainable development model of MOOC; SPOC redefines the role of teachers and innovates the teaching model; SPOC puts more emphasis on students' complete and in-depth learning experience, which is conducive to improving the completion rate of the course. Based on a systematic comparison of the differences between MOOC and SPOC, they elaborated on several typical practical applications of SPOC at home and abroad. The case explored the design of a hybrid classroom teaching model based on the Pan-Asian SPOC. The teaching theory was fully used in the platform, and the model including front-end analysis, curriculum design, curriculum organization, and teaching "four-core" evaluation was analyzed in detail [5]. In addition, some scholars have organically integrated classroom teaching and online learning by constructing a SPOC hybrid teaching model and developed a flipped classroom. From "teaching as the center" to "learning" "centered," the new classroom assessment mode adopts a variety of assessment methods to effectively ensure the quality of classroom teaching according to the learning characteristics, professional background, and learning requirements of students, so as to promote students' independent learning [6]. The results provide theoretical guidance for the research of this article.

Based on the literature review, this article will explore mixed oral English based on the SPOC and deep learning mixed mode by comparing and analyzing the oral English situation of the students in the experimental class and the control class before and after the experiment, as well as the evaluation of the mixed mode teaching. Deep learning technology can be used to verify the effectiveness of the teaching. Deep learning has made many achievements in search technology, data mining, machine learning, machine translation, natural language processing, multimedia learning, voice, recommendation and personalization technology, and other related fields. Deep learning makes machines imitate human activities such as audiovisual and thinking, solves many complex pattern recognition problems, and makes great progress in artificial intelligence-related technologies.

\section{Research on the Evaluation of Blended Oral English Teaching Based on the Hybrid Model of SPOC and Deep Learning}

\subsection{The Teaching Design Principles of the Hybrid Model of SPOC and Deep Learning}

2.1.1. Teacher-Led and Student-Oriented Principles. The traditional classroom teaching model in our country has long tended to be teacher-centered, focusing on giving play to the leadership role of teachers in the classroom. However, under such an education system, the initiative of students is constantly weakening, which is not conducive to the enthusiasm and creativity of students. The blended learning model not only reflects the leading role of teachers in education but also has a complete impact on the subjectivity of students. The design of the blended learning model should adhere to the student-centered principle. In the education process, students are the main body of learning, and teachers are only assistants. Teachers need to design logical courses, encourage students to learn actively and continuously, and cultivate their independent learning ability and innovative consciousness. Through the blended learning model, the teacher-led and student-based subjects are deeply integrated, and finally, an excellent educational effect is achieved [7, 8]. One of the important characteristics of teaching different from other cognition or learning activities is that students' cognition is carried out under the guidance of teachers. Teachers have received special education and training. They understand the purpose of teaching and master the contents and methods of teaching. Therefore, it is objectively inevitable for teachers to play a leading role. In the process of teaching, students are the main body of cognitive or learning activities. Therefore, students' initiative, enthusiasm, and creativity are also the necessary conditions for successful teaching.

2.1.2. The Principle of Integrity. Blended learning is a teaching method that combines the advantages of traditional classroom teaching and online learning. This way of design needs to include front-end analysis, learning process design, learning evaluation design, and many other links. Each link is interrelated and cannot be separated. Only when all links work together can the overall function be completed $[9,10]$.

2.1.3. Evaluative Principle. As the name suggests, online education is a teaching method based on the network. Through the network, students and teachers can carry out teaching activities even if they are thousands of miles apart; in addition, with the help of network courseware, students can study anytime and anywhere, which really breaks the restrictions of time and space. For workplace people with busy work and uncertain learning time, network distance education is the most convenient way of learning.

All education models are inseparable from an objective evaluation mechanism. Evaluation mechanisms play an important role in the design of complex learning models. The traditional education model often regards the student's academic performance as the only criterion for evaluating students, while the mixed learning model requires the use of multiple evaluation methods. When evaluating students, not only the academic performance of the students must be considered but also the sexual evaluation. Formative evaluation helps students maintain self-confidence, maintain enthusiasm for learning, and promote student learning. Therefore, when designing a hybrid learning model, the principle of evaluation should always be considered, and the model should be continuously improved based on the results of evaluation and feedback [11, 12].

\subsection{SPOC and Deep Learning Hybrid Model Teaching Evaluation Construction Principles}

2.2.1. Principle of Consistency with the Target. Indicators are expressed as specific, behavioral, and functional goals. These 
goals must be fully reflected and highly consistent with training goals or daily management standards. Consistency with the target refers to the consistency of the indicators in the system. The SPOC scoring index system based on the perspective of deep learning avoids the combination of two conflicting indicators, so as not to confuse the evaluator and fail to make an accurate evaluation of the SPOC. The principle of unity of objectives means that the more the contribution of all departments and members in the organization is conducive to the realization of the organization's objectives, the more reasonable the organization's structure is. Organization is a cooperative system created to achieve goals. The establishment of an organization is the means to achieve goals. The common goal is the objective basis for the establishment and existence of an organization. Without a common goal, it is impossible to establish an organization. Even if it is established temporarily, it is impossible to survive for a long time. Only with clear and consistent goals can all departments and members of the organization have the basis for cooperation and common direction of action; otherwise, there can be neither intention nor action of cooperation. The common goal is also the objective basis for improving and developing the organization. The improvement and development of the organization must be based on the realization of common goals; otherwise, it will destroy the organization.

2.2.2. Concise and Scientific Principles. The evaluation of SPOCs should follow scientific principles and objectively and honestly reflect the characteristics and current situation of SPOCs from a detailed learning perspective. This enables the evaluation to truly reflect the current problems of the university's SPOC curriculum, the indicators are not easy to be too complicated, convenient for students to observe and measure, combined with the characteristics of deep learning, improve the curriculum, promote the development of university SPOCs, and enable deep learning in the education team, and the emergence of individual students cultivates practical and creative talents who can solve complex problems.

\subsubsection{Principles from the Perspective of Deep Learning.} When determining the dimensions of the scoring indicators and the specific elements of the scoring indicators, we should start from the perspective of deep learning, comprehensively consider the factors that affect the deep learning of SPOCs, analyze the data, and extract the grading index from the perspective of deep learning to examine its accurate expression so that evaluators have accurate positioning and understanding of indicators when evaluating courses with reference to standards. The calculation involved in generating an output from an input can be represented by a flowchart: the flowchart is a graph that can represent the calculation. In this graph, each node represents a basic calculation and a calculated value, and the calculated results are applied to the values of the child nodes of this node. Consider such a calculation set, which can be allowed in each node and possible graph structure, and define a function family. The input node has no parent nodes, and the output node has no child nodes.

\section{Experiment}

3.1. Subjects. In order to verify the feasibility and effectiveness of the mixed teaching model designed in this article, this article has conducted a half-semester teaching survey on two classes of non-English majors in a university and studied the mixed teaching of SPOC and deep learning through the method of covariance analysis. We study the impact of this model on student performance and the development of oral English and analyze the effectiveness of this model from the perspective of teachers and students. Before the implementation of the teaching model, this article first investigated the prespeaking test scores of non-English majors as a comparison for follow-up research. In the following practice, this article will use one class as the control class and the other as the experimental class. The two classes have the same learning foundation, and there is no difference in the ratio of men to women, the content of the teaching materials, the teaching progress, and the oral level.

Covariance analysis is also called "covariate (number) analysis." Analysis of covariance is essentially the extension and expansion of analysis of variance. The basic principle is to combine linear regression with analysis of variance, adjust the average of each group and the experimental error term of the $F$-test, and test whether there is a significant difference between two or more adjusted averages, so as to control the influence of covariates (variables with a close regression relationship with dependent variables) that affect the experimental effect (dependent variables) in the experiment and are not controlled by legal person in the analysis of variance. Covariance is an overall parameter used to measure the "collaborative variation" between two variables, that is, the parameter of the interaction between two variables. The greater the absolute value of covariance, the greater the interaction between two variables.

\subsection{Experimental Process}

3.2.1. Before the Experiment. Before the experiment, the students in the control class and the experimental class received a three-week oral training on a regular basis, and students are organized to take pretraining exams. The preexamination paper has a total of 100 units, and each student takes about 6 minutes to take the exam. The test paper is divided into self-introduction parts. The second part is the keynote speech. The third part is the question and answer session.

3.2.2. In the Experiment. In the course of the experiment, the control class adopts the method of oral teaching with the help of multimedia courses. Teachers integrate resources for oral teaching planning during SPOC classroom preparation, and teachers guide students to use the internet and other channels to find resources for self-preparation. In the classroom, through collaborative learning and group 
discussions, special lectures, and status presentations, the ability to use spoken English is cultivated. Teachers encourage students to participate in interactive discussions to improve their ability to use spoken English.

3.2.3. After the Experiment. After the experiment, the students in the control class and the experimental class will take the posttest exam. The postexperiment test consists of three parts. The first part is self-introduction, the second part is a keynote speech, and the third part is a question and answer session. The test time per life is 6 minutes.

3.3. Data Processing. In order to improve the reliability and validity of the experimental data, this article discusses the use of the covariance analysis method in SPSS 17.0 to statistically analyze the data scored by the two classes before and after the exam. The predicted results are analyzed as the covariance. Note that SPSS is the earliest statistical software in the world that uses a graphical menu-driven interface. Its most prominent feature is that the operation interface is very friendly, and the output results are beautiful. It shows almost all functions in a unified and standardized interface and uses the Windows window to show the functions of various data management and analysis methods, and the dialog box shows various function options. As long as users master certain Windows operation skills and master the principle of statistical analysis, they can use software to serve specific scientific research work. The regression model is used to verify the results of the pretest, and the oral teaching method based on the flipped classroom has a predictive effect on the teaching effect after the experiment; thus, the impact of the flipped classroom oral teaching method on its performance in the postexperiment evaluation is established. The calculation process of the covariance analysis method is as follows:

$$
Y-X_{2} \beta=X_{1} \alpha+e .
$$

According to formula (1), find the least square estimate of $\alpha$ :

$$
\alpha=\left(X_{1}^{T} X_{1}\right)^{-1} X_{1}^{T}\left(Y-X_{2} \beta\right)
$$

From $Y-X_{2} \beta=X_{1} \alpha+e$, find the least square estimate of $\beta$ :

$$
\beta=\left(X_{2}^{T} X_{2}\right)^{-1} X_{2}^{T}\left(Y-X_{1} \alpha\right)
$$

Among them, $X_{1} \alpha$ is the variance analysis part of the model, and $X_{2} \beta$ is the regression part of the model.

\section{Discussion}

4.1. Comparison of Learning Interests. In order to verify the influence of this teaching model on students' learning interest, after the experiment, this article surveyed the students' oral learning interest in the two classes in the pretest questionnaire and compared the students' oral learning interest before and after the experiment.
According to Table 1 and Figure 1, it can be seen that the learning interest of the students in the control class has improved before and after the experiment, but the data changes are not significant, indicating that, after a semester of study, the students' interest in oral learning in the control class has not changed much. $36.777 \%$ of the students in the experimental class strongly agreed that the SPOC teaching model stimulated their interest in learning, and $46.77 \%$ of the students agreed that this teaching model enhanced their interest in learning, which was an increase of $16.67 \%$ from before the experiment. It can be seen that SPOC blended teaching has a very obvious effect on stimulating students' interest in learning, and the SPOC blended teaching model has a greater role in promoting students' interest in learning.

4.2. Comparison of Learning Effects. After a semester of teaching practice, this article compares and analyzes the oral learning effects of the experimental class and the control class based on the posttest questionnaire survey results and the oral test results. The situation is as follows.

According to Table 2 and Figure 2, it can be concluded that $14.28 \%$ of the control class think that their oral expression ability has been greatly improved, and $21 \%$ of the experimental class and $32.13 \%$ of the control class think that their oral proficiency has been improved. There are $47.67 \%$, $17.88 \%$, and $6.68 \%$ of the students in the control class and the experimental class who think that their oral expression skills have not been improved, and the proportion of the number of students in the experimental class is significantly larger than that in the control class.

According to Figure 3, the average score of the oral test of the experimental class is 81.76 , and the average score of the control class is 70.35. Compared with the scores of the previous test, the scores of both classes have improved, and the scores of the experimental class have increased by approximately 12 points, the results of the control class increased by about 5 points, and the results of the experimental class improved even more, indicating that the mixed oral English teaching based on the mixed mode of SPOC and deep learning is effective.

4.3. Comparison of Deep Learning Capabilities. The change of deep learning ability is used as the main criterion to evaluate the mixed oral English teaching based on SPOC and deep learning. The method of evaluation is through the deep learning ability questionnaire before and after the teaching of the experimental group students and collecting data, comparing SPOC and deep learning. The relationship between the mixed mode and the difference of the students' deep learning ability before and after the teaching mode is not implemented. Note that cognition includes feeling, perception, memory, thinking, imagination, and language. Specifically, the process of acquiring or applying knowledge begins with feeling and perception. Feeling is the understanding of the individual attributes and characteristics of things. Traditionally, it refers to the cognitive process, which refers to the psychological process in which the human brain reflects the characteristics and relations of objective things in 
TABLE 1: Changes in learning interest of the two classes before and after the experiment.

\begin{tabular}{lcccc}
\hline & $\begin{array}{c}\text { Control class before the } \\
\text { experiment (\%) }\end{array}$ & $\begin{array}{c}\text { Control class after the } \\
\text { experiment (\%) }\end{array}$ & $\begin{array}{c}\text { Experimental class before the } \\
\text { experiment (\%) }\end{array}$ & $\begin{array}{c}\text { Experimental class after the } \\
\text { experiment (\%) }\end{array}$ \\
\hline $\begin{array}{l}\text { Incompatible } \\
\begin{array}{l}\text { Not very } \\
\text { consistent }\end{array}\end{array}$ & 3.58 & 3.67 & 3.23 & 0 \\
$\begin{array}{l}\text { Basically accord } \\
\text { with }\end{array}$ & 14.31 & 7.2 & 9.8 & 3.23 \\
$\begin{array}{l}\text { Conform to } \\
\begin{array}{l}\text { Very much in } \\
\text { line }\end{array}\end{array}$ & 46.42 & 46.33 & 46.77 & 30.1 \\
\hline
\end{tabular}

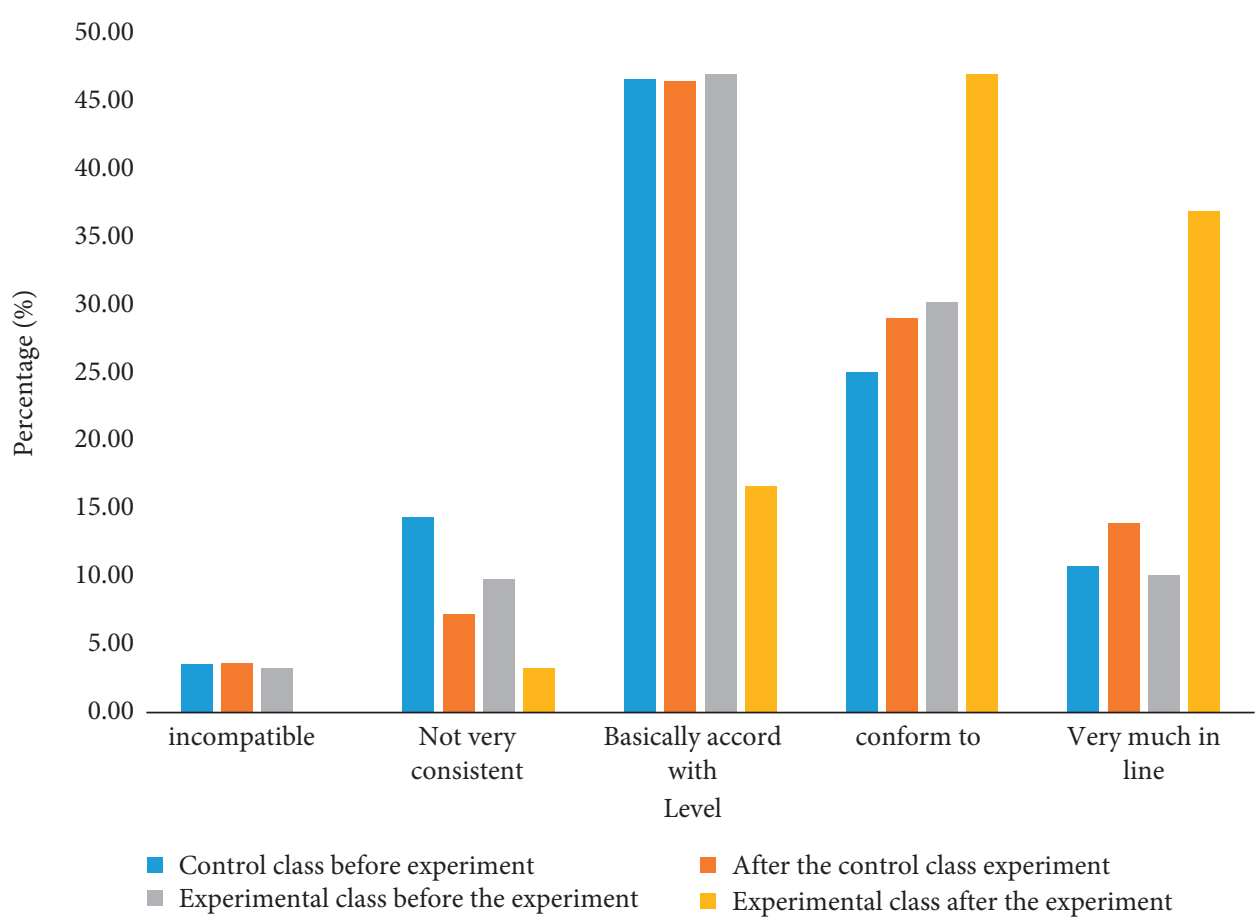

FIGURE 1: Changes in learning interest of the two classes before and after the experiment.

TABLE 2: Comparison of students' oral English improvement in two classes.

\begin{tabular}{lcc}
\hline & Control class (\%) & Experimental class (\%) \\
\hline Very much in line & 14.28 & 21 \\
Conform to & 32.13 & 47.67 \\
Basically accord with & 28.56 & 21.33 \\
Not very consistent & 17.88 & 6.68 \\
Incompatible & 7.15 & 3.32 \\
\hline
\end{tabular}

the form of perception, memory, and thinking. In cognitive psychology, information processing refers to the process in which individuals receive, encode, store, extract, and use information.

It can be seen from Table 3 and Figure 4 that the pretest average in the cognitive domain is 3.64 , and the posttest average is 3.70 ; the pretest average in the interpersonal domain is 3.68 , and the posttest average is 3.74 ; the pretest average in the personal domain is 3.81 , and the posttest average is 3.84 .
As can be seen from Table 4 and Figure 5, the cognitive domain correlation coefficient is 0.94 , the $t$-value of the paired sample test is -5.264 , and the significance $p=0.000<0.01$, showing a significant difference at the level of 0.01 ; the interpersonal domain correlation coefficient is 0.961 , the $t$-value of the paired sample test is -5.352 , and the significance $p=0.000<0.01$, showing a significant difference of the 0.01 level; the personal field correlation coefficient is 0.968 , the $t$-value of the paired sample test is -4.310 , and the significance 


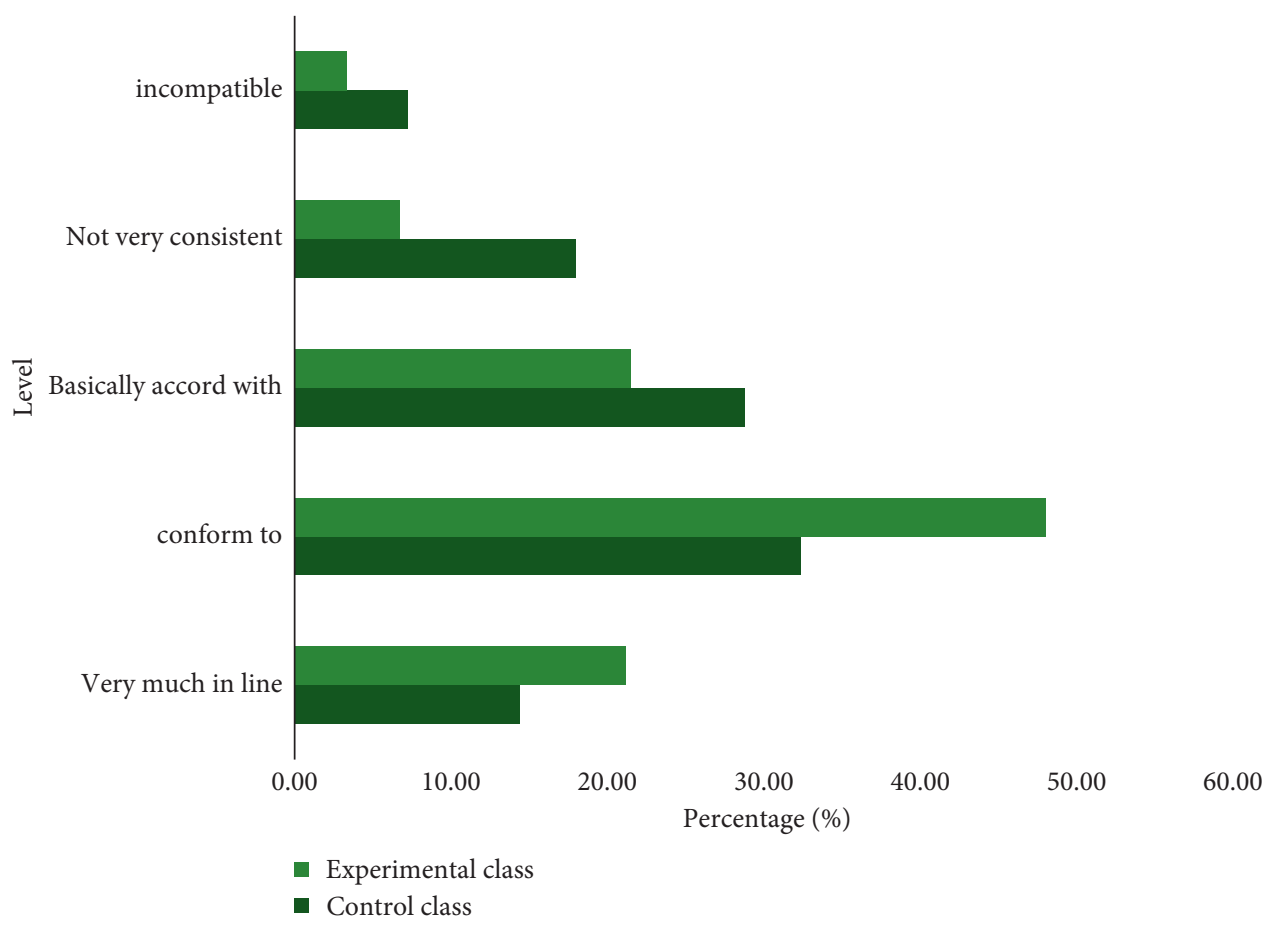

FIgURE 2: Comparison of students' oral English improvement in two classes.

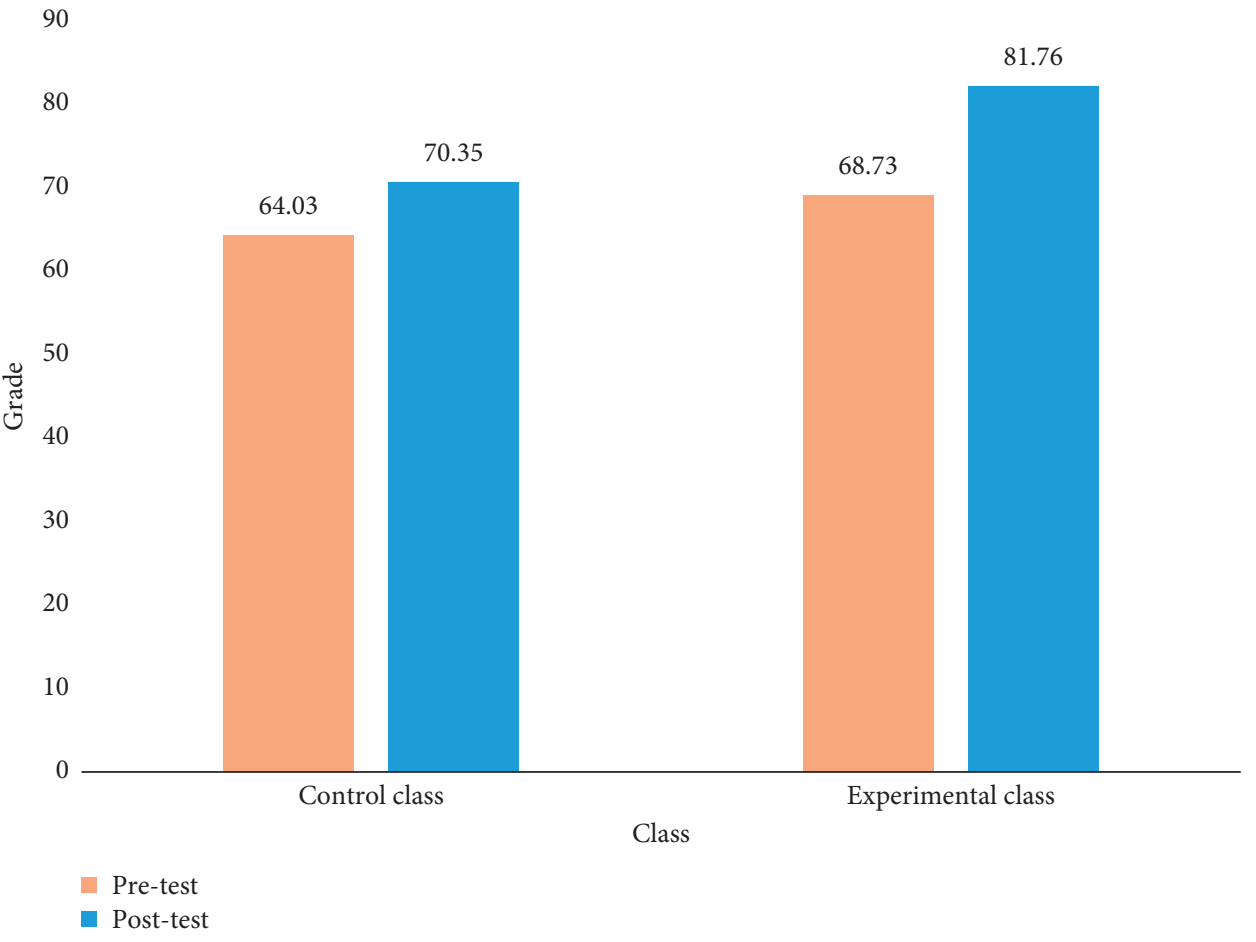

FIgURE 3: Comparison of two and a half oral test scores. 
Table 3: Paired sample statistics.

\begin{tabular}{lcccc}
\hline & & Average value & Standard deviation & Standard deviation \\
\hline \multirow{2}{*}{ Pairing 1 } & Cognitive front & 3.64 & 0.742 & 0.036 \\
& Cognitive posttest & 3.70 & 0.633 & 0.031 \\
\hline \multirow{2}{*}{ Pairing 2 } & Interpersonal pretest & 3.68 & 0.968 & 0.045 \\
& Interpersonal posttest & 3.74 & 0.890 & 0.041 \\
\hline \multirow{2}{*}{ Pairing 3 } & Individual front & 3.81 & 0.834 & 0.035 \\
& Individual posttest & 3.84 & 0.780 & 0.033 \\
\hline
\end{tabular}

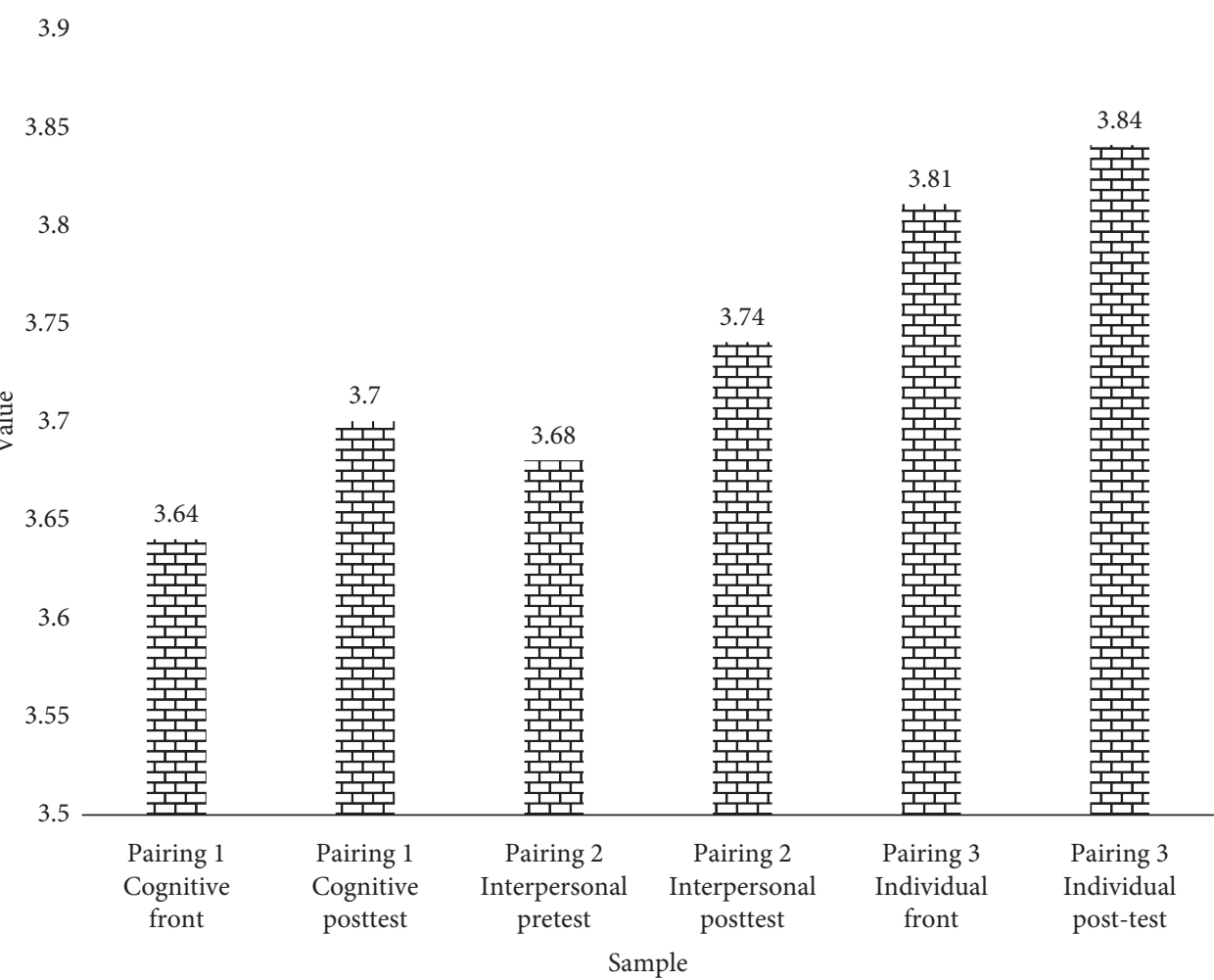

ᄃ average value

FIgURE 4: Paired sample mean.

TABLE 4: Paired sample testing and correlation.

\begin{tabular}{lccccc}
\hline & & Average value & $t$ & Correlation & Significance \\
\hline Pairing 1 & Cognitive front-cognitive posttest & -0.063 & -5.264 & 0.940 & 0.000 \\
Pairing 2 & Interpersonal pretest-interpersonal posttest & -0.059 & -5.352 & 0.961 & 0.000 \\
Pairing 3 & Individual front-individual posttest & -0.032 & -4.310 & 0.968 & 0.000 \\
\hline
\end{tabular}

$p=0.000<0.01$, showing a significant difference at the level of 0.01; these data show that, after half a semester of teaching practice, the mixed oral English teaching based on the SPOC and deep learning mixed mode has a critical thinking and responsible problem-solving ability for students, teamwork, and effective communication; independent learning and self-reflection have all had a positive impact. 


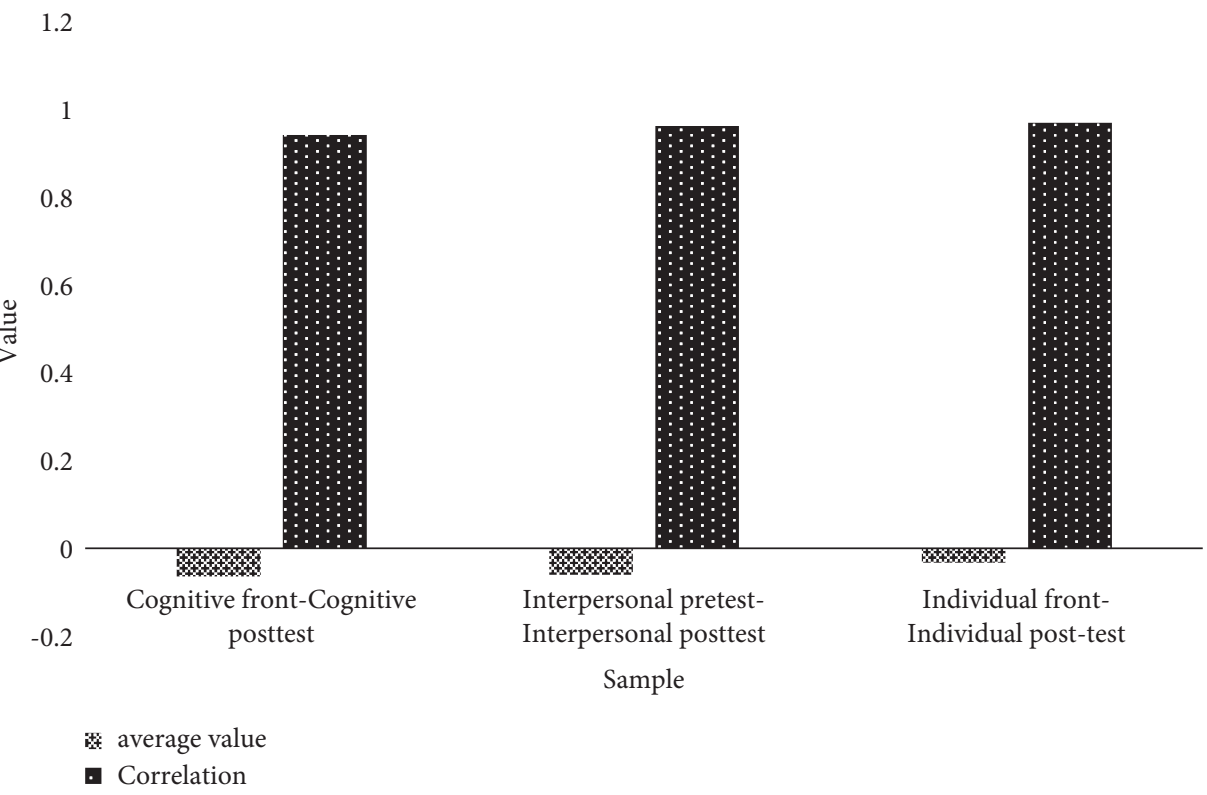

Figure 5: Paired sample mean and correlation.

\section{Conclusions}

The rapid development of education informatization has brought new opportunities and challenges for teachers. Network learning, mobile learning, and other means make students' classroom activities present rich and diverse characteristics. Excellent teachers need to keep pace with the times, strengthen education and maintenance, strive to create a good learning atmosphere for everyone, and enhance everyone's learning effect. The "SPOC + deep learning" hybrid model of college spoken English provides a reference for public classroom education. When designing online or offline classroom forms, you can fully consider the use of high-level thinking activities such as analysis, evaluation, and innovation to promote students' deep learning and further improve the effect of learning. Through the labeled data to train, the error is transmitted from top to bottom to fine-tune the network. Based on the parameters of each layer obtained in the first step, the parameters of the whole multilayer model are further optimized. This step is a supervised training process. The first step is similar to the random initialization initial value process of the neural network. Because the first step is not random initialization, but obtained by learning the structure of input data, this initial value is closer to the global optimization, so it can achieve better results. Therefore, the good effect of deep learning is largely due to the first step of feature learning.

\section{Data Availability}

The raw data supporting the conclusions of this article will be made available by the author, without undue reservation.

\section{Conflicts of Interest}

The author declares that there are no conflicts of interest regarding this work.

\section{References}

[1] J. Simarmata, A. Djohar, J. Purba, and E. A. Juanda, "Design of a blended learning environment based on merrill's principles," Journal of Physics: Conference Series, vol. 954, no. 1, Article ID 012005, 2018.

[2] C. Dziuban, C. R. Graham, P. D. Moskal, A. Norberg, and N. Sicilia, "Blended learning: the new normal and emerging technologies," International Journal of Educational Technology in Higher Education, vol. 15, no. 1, p. 3, 2018.

[3] M. H. T. Kho, K. S. Chew, M. N. Azhar et al., "Implementing blended learning in emergency airway management training: a randomized controlled trial," BMC Emergency Medicine, vol. 18, no. 1, p. 1, 2018.

[4] R. . Owston, "Empowering learners through blended learning," International Journal on E-Learning, vol. 17, no. 1, pp. 65-83, 2018.

[5] N. Popovic, T. Popovic, I. Rovcanin Dragovic, and O. Cmiljanic, "A Moodle-based blended learning solution for physiology education in Montenegro: a case study," Advances in Physiology Education, vol. 42, no. 1, pp. 111-117, 2018.

[6] M. D. R. C. Alcántar and J. C. Montes, "Percepción de los Estudiantes sobre el Aprendizaje Significativo y Estrategias de Enseñanza en el Blended Learning[J]," Reice Revista Iberoamericana Sobre Calidad Eficacia Y Cambio En Educación, vol. 16, p. 1, 2018.

[7] Z. Fakhir and M. A. Ibrahim, "The effect of blended learning on private school students' achievement in English and their attitudes towards it," English Language and Literature Studies, vol. 8, no. 2, p. 39, 2018.

[8] J. C. Almenara and V. Marín-Díaz, "Blended learning y realidad aumentada: experiencias de diseo docente Blended learning and augmented reality: experiences of educational design," RIED. Revista Iberoamericana de Educación a Distancia, vol. 21, no. 1, pp. 57-74, 2018.

[9] M. P. Bergstr and V. Lindh, "Developing the role of Swedish advanced practice nurse (APN) through a blended learning master's program: consequences of knowledge organisation," Nurse Education in Practice, vol. 28, pp. 196-201, 2018. 
[10] R. Crawford, L. Jenkins, and L. Jenkins, "Making pedagogy tangible: developing skills and knowledge using a team teaching and blended learning approach," Australian Journal of Teacher Education, vol. 43, no. 1, pp. 127-142, 2018.

[11] K. Matheos and M. Cleveland-Innes, "Blended learning: enabling higher education reform," Revista Eletrônica de Educação, vol. 12, no. 1, pp. 238-244, 2018.

[12] H. Shu and X. Gu, "Determining the differences between online and face-to-face student-group interactions in a blended learning course," The Internet and Higher Education, vol. 39, pp. 13-21, 2018. 